\title{
Erratum to: Data sources for identifying low-income, uninsured populations: application to public health-National Breast and Cervical Cancer Early Detection Program
}

\author{
Lucinda P. Dalzell ${ }^{1}$ - Florence K. L. Tangka ${ }^{2}$ David S. Powers ${ }^{1}$. \\ Brett J. O'Hara ${ }^{1} \cdot$ Walter Holmes ${ }^{1} \cdot$ Kristy Joseph $^{3} \cdot$ Janet Royalty $^{2}$
}

Published online: 5 May 2015

(c) Springer International Publishing Switzerland 2015

\section{Erratum to: Cancer Causes Control DOI 10.1007/s10552-015-0571-y}

In the original publication of the article, references 14 and 15 have not been cited properly. The corrected references are given below.

\section{References}

14. Tangka FKL, Howard D, Royalty J, Dalzell LP, O'Hara B, Miller $\mathrm{J}$ et al (2015) Cervical cancer screening of underserved women in the United States: results from the National Breast and Cervical Cancer Early Detection Program, 1997-2012. Cancer Causes Control. doi:10.1007/s10552-015-0524-5

15. Howard D, Tangka FKL, Royalty J, Dalzell LP, Miller J, O'Hara B, Joseph K, Kenney K, Guy G, Hall IJ (2015) Breast cancer screening of underserved women in the United States: results from the National Breast and Cervical Cancer Early Detection Program, 1998-2012. Cancer Causes Control. doi:10.1007/ s10552-015-0553-0

The online version of the original article can be found under doi:10.1007/s10552-015-0571-y.

Lucinda P. Dalzell

lucinda.p.dalzell@census.gov

1 Social, Economic and Housing Statistics Division, 6H123,

U.S. Census Bureau, 4600 Silver Hill Road, Washington,

DC 20233-8500, USA

2 Division of Cancer Prevention and Control, National Center for Chronic Disease Prevention and Health Promotion, Centers for Disease Control and Prevention, MS F-76, Atlanta, GA 30341, USA

3 Noncommunicable Disease Unit, Division of Global Health Protection, Center for Global Health, Centers for Disease Control and Prevention, MS E-93, Atlanta, GA 30329, USA 